\title{
NO HE VENIDO A SER SERVIDO SINO A SERVIR
}

\author{
Mons. Alejandro Goic \\ Obispo de Osorno
}

Queridas hermanas, queridos hermanos:

\section{Querido Sergio:}

¡Qué bueno es estar los hermanos juntos! Asi comienza uno de los salmos de la Santa Biblia. Hoy, nosotros, podemos repetir con el salmista ¡qué bueno es estar los hermanos juntos! Juntos hermanos creyentes laicos, juntos hermanos consagrados y pastores, para alabar y bendecir a Dios por su amor para con nosotros; juntos para bendecir y agradecer a Dios por el servicio de pastor de nuestro querido hermano y amigo Sergio; juntos para agradecer sus 44 años de generosa vida sacerdotal, de los cuales 35 como Obispo: 7 como Obispo de Ancud, 4 como Obispo Auxiliar de Concepción y casi 24 años como pastor de esta Iglesia Diocesana de Temuco.

La Palabra de Dios que hemos acogido hoy ilumina nuestra alabanza y nuestra gratitud a Dios: El profeta Isaias recuerda la misión que recibió de Dios y que después en el N.T. Jesús el Salvador retomará para señalar que la plenitud de esa misión y de esa salvación se realiza en Él, el enviado del Padre. San Pedro, el amigo de Jesús y llamado por Él a confirmar a sus hermanos en la fe, nos recuerda en su carta que los dones recibidos de Dios sean usados para el bien de los demás, haciéndolos fructificar con generosidad y que en todo y sobre todo Dios sea glorificado. Jesús en su Evangelio, señala claramente el estilo del discipulo, cualquiera sea la responsabilidad que ejerza en la Iglesia o en la sociedad a "imitación del Hijo del Hombre que no vino para que lo sirvieran, sino para servir y dar su vida como rescate de una muchedumbre" (Mt. 20,28)

Esta Palabra de Dios ha inspirado e iluminado el ministerio sacerdotal y episcopal, a quien hoy con inmensa gratitud, esta Iglesia de Temuco, despide como su Padre y Pastor. Culmina para nuestro querido hermano

1 Texto de la homilia pronunciada con ocasión de la despedida de don Sergio (27/10/2001). 
Sergio su misión de pastor en esta Iglesia Particular y comienza una nueva etapa, donde, desde la profundidad de su fe y de su entrega, seguirá haciendo el bien a otros hermanos.

Esta Palabra de Dios que es la que orienta el caminar de los creyentes y de la Iglesia a lo largo de su historia, fue la que inspiró a los Obispos en el Concilio Vaticano II y luego en nuestra realidad latinoamericana; en 1968 en Medellin, en 1979 en Puebla y en 1992 en Santo Domingo. Y de esa palabra magisterial surgió nitida la figura del Obispo para los nuevos tiempos. Justo, a un año de terminado el Concilio, nuestro hermano Sergio en 1966 recibió el llamado de Dios y de su Iglesia a ser Obispo. Es un Obispo de! Concilio Vaticano II y de las diversas conferencias episcopales de América Latina.

Lo que hizo el Concilio y las diversas asambleas generales del Celam, fue rescatar del Evangelio la originalidad del ministerio episcopal y darle su verdadera dimensión. El Concilio recordó claramente la vida y misión del pastor en la Iglesia. Y la mirada se centró en el Único Buen Pastor que es Jesús. Por eso, el pastor en una Igiesia particular va delante de las ovejas, da la vida por ellas para que tengan vida y la tengan en abundancia. "Conocer las ovejas y ser conocidos por ellas, no se limita a saber de las necesidades de los fieles. Conocer es involucrar el propio ser, amar como quien vino no a ser servido, sino a servir" (P. 684). El Obispo es maestro de la verdad, signo y constructor de la unidad, pontifice y santificador. $Y$ hace "de su vida gozosa, austera, sencilla y lo más cercana posible de su pueblo. un testimonio de Cristo Pastor y un medio de diálogo con todos los hombres" (P. 689)

$\mathrm{Si}$, lo afirmo con fuerza y claridad. Nuestro amigo y hermano Sergio, es un Obispo del Concilio Vaticano II. Después de haber finalizado de manera brillante sus estudios de Ingenieria en la Universidad Técnica Federico Santa Maria, sirvió como asesor diocesano en Valparaiso de los universitarios, luego como asesor diocesano y nacional de la JOC y viceasesor nacional de la ación católica del Pais. A los 40 años el Papa Pablo VI lo eligió como Obispo de Ancud. Durante siete años recorrió toda la geografia del Archipiélago, tomando contacto con todas las comunidades y personas de esa hermosa región de nuestro Chile. Un Obispo en terreno, misionero, cercano a la gente. Y luego continuará en esa misma linea en la Arquidiócesis de Concepción por cuatro años, como Obispo Auxiliar. En la lógica del mundo era extraño. Pasar de responsable de una Diócesis a colaborador del Arzobispo de Concepción, como Obispo Auxiliar. En la lógica del Evangelio se trataba de otra cosa. De servir. No se hizo sacerdote para "hacer carrera", sino para dar su vida al servicio del pueblo de Dios. Me tocó recoger su herencia de pastor en Concepción cuando en 1979 llegué a servir ahí como Obispo Auxiliar. Ahi se le recordaba con cariño. La fuerza de su palabra, la defensa apasionada de la dignidad humana en esos años duros y dificiles, la puesta en marcha de una organización pastoral ágil â servicio del anuncio de Evangelio. 
Y luego, han venido estos casi 24 años aqui en Temuco. Ustedes hermanos laicos, religiosas, diáconos y sacerdotes, saben muy bien de su ministerio y de su entrega. Ustedes son testigos. Ustedes pueden dar testimonio de lo que ha significado este pastor bueno, sencillo y valiente para esta Iglesia particular. Ustedes saben como ha recorrido esta tierra animando y fortaleciendo las comunidades eclesiales de base; ustedes conocen como ha impulsado la pastoral vocacional y ha fortalecido el cuerpo presbiteral y diaconal en estos años; ustedes son testigos de su defensa de la dignidad humana, de su preocupación por todos los problemas sociales y particularmente de la dignidad de los pueblos indigenas, por quienes siempre ha alzado la voz e impulsado iniciativas de todo tipo para su integración a la comunidad nacional; ustedes pueden dar testimonio como todos los gozos y los dolores de esta tierra bendita han sido sus propios gozos y sus propios dolores; ustedes saben como ha puesto toda su capacidad e inteligencia al servicio de la Iglesia y de la sociedad; ustedes pueden decir de su amor a Jesucristo, a su Evangelio y de toda la actividad misionera desplegada estos años para que Jesucristo sea conocido, amado y seguido. Si, queridos hermanos, ustedes son testigos de la entrega de este pastor, que en fidelidad al Único Pastor, "no vino a ser servido sino a servir".

Y nosotros, los Obispos de Chile, los de ayer y los de hoy, somos también testigos, de su admirable entrega, inteligencia y aporte a la Iglesia y al Pais. Ha ocupado diversos cargos en la Conferencia Episcopal de Chile, en la Comisión Pastoral y en el Comité Permanente: nueve años fue Secretario General; participó en Conferencias Generales de América Latina y en Sinodos en Roma. Toda la vida de la Iglesia y del Pais y del mundo, como los grandes problemas y situaciones de la realidad, estuvieron siempre presentes en su reflexión y en sus aportes. Nada de lo humano le ha sido ajeno, todo ha encontrado eco en su corazón de pastor. Atento a los signos de los tiempos para descubrir el paso de Dios en nuestra historia. Con mirada de futuro y de esperanza.

Llevo 22 años participando en la Cech, en sus Asambleas Plenarias, en los Organismos Nacionales. Doy testimonio y estoy seguro, todos los hermanos Obispos conmigo, que la orientación de la Iglesia en Chile en las últimas décadas y su fidelidad a Jesucristo y su servicio a todos, especialmente a los pobres y sufrientes es en parte, junto con otros, fruto del aporte y de la reflexión del Obispo Sergio. ¡Admirable su constancia, inteligencia y fortaleza para seguir todos los temas! ¡Admirable su búsqueda de descubrir la presencia salvadora de Dios en los acontecimientos y de vivir el ministerio episcopal con talante evangélico, al modo de Jesucristo!

Lo que venimos diciendo $-\mathrm{y}$ mucho más que podriamos decir- no es para ensalzar a un hombre ¡conocemos la sencillez de corazón de Sergio!, sino para bendecir a Dios por lo que va haciendo en sus hijos, en un hijo que le entregó toda su vida, un hermano nuestro que en la flor de su juventud sintió la fascinación de Jesucristo y se enamoró de Él y le entregó todo. Ahi 
radica la fuerza y la vitalidad de este pastor bueno que Temuco despide lleno de gratitud. Cada mañana, al comenzar el día, Sergio, nuestro Obispo, entra en ese diálogo de amor y de intimidad de comunión y esperanza con el Dios que le amó primero y que le llamó a ser pastor en relación con el Único Pastor. De esa intimidad ha extraído y extrae la fuerza y el coraje evangélico para servir y dar la vida por su pueblo, en el convencimiento más hondo que es necesario que Jesucristo crezca en el corazón y en la vida de la gente y que èl, su persona y su ministerio desaparezca. En el convencimiento más absoluto que la fe es energía histórica, que incide en la vida humana, en la vida social, que el cristianismo es fuerza para una verdadera liberación de todas las esclavitudes, como hoy lo recordaba Isaias y como se hizo realidad en Jesucristo y en su Pascua salvadora.

Sergio, nuestro Obispo, que hoy despedimos con inmensa gratitud $y$. ciertamente, ¡somos humanos!, con pena y nostalgia, nos ha mostrado con su vida y con su palabra que la grandeza de un ser humano, en clave de fe, no radica en las obras que uno realiza, sino en hacerse uno mismo, por gracia de Dios, obra de sus manos. Eso ha sido Sergio para la Iglesia en Chile y en particular para Temuco: ha sido "pontifice", es decir, ha sido un puente, por el que miles y miles de seres humanos han atravesado para permitir el encuentro, en la otra orilla, con el que verdaderamente salva y da la vida verdadera: Jesucristo, Señor y Salvador.

A Jesucristo, Único Salvador, honor y gloria por los siglos de los siglos. Amén. 